\title{
PENGARUH GAYA BELAJAR TERHADAP PENGUASAAN KOSAKATA BAHASA INGGRIS
}

\author{
Natalia Tri Astuti \\ Teknik Informatika, Fakultas Teknik Matematika dan Ilmu Pengetahuan Alam \\ Universitas Indraprasta PGRI \\ natnatalia.lia@gmail.com
}

\begin{abstract}
The aim of the research is to know the effect of learning style towards to vocabulary building students in Mardi Yuana Bogor Junior High School. The Hypotheses is tested are the student's English vocabulary with auditory, kinestetic, and visual learning style. The Method of the Research is quantitative method to know how the effect of learning style towards to student's vocabulary building by the SPSS 16.0 program. Sample of this research are 64 students class VIII Mardi Yuana Junior High School. According to the research with SPSS 16.0 program when $\alpha=0,05$ we get sig 0,000 $<0,05$ and Fhit $>$ Ftable or 16,544 > 3,148. So that Ho is refused and $\mathrm{H} 1$ is received. Its mean there is a good effect of learning style towards to student's vocabulary building.
\end{abstract}

Key Words: Learning Style, Auditory, Kinestetic, Visual, Vocabulary

\begin{abstract}
Abstrak
Penelitian ini bertujuan untuk mengetahui pengaruh dari gaya belajar terhadap penguasaan kosakata bahasa Inggris peserta didik kelas VIII SMP Mardi Yuana Bogor. Hipotesis yang diuji adalah terdapat perbedaan penguasaan kosakata bahasa Inggris peserta didik dengan gaya belajar auditori, kinestetik dan visual. Metode penelitian yang digunakan adalah metode penelitian kuantitatif untuk mengetahui seberapa besar pengaruh gaya belajar terhadap penguasaan kosakata bahasa Inggris peserta didik dengan dibantu SPSS 16.0. Sampel pada penelitian ini adalah 64 peserta didik kelas VIII SMP Mardi Yuana Bogor. Berdasarkan hasil penelitian dengan SPSS 16.0 pada taraf signifikansi $\alpha=0,05$ diperoleh nilai sig $0,000<0,05$ dan Fhit $>$ Ftab atau 16,544 > 3,148. Maka Ho ditolak dan H1 diterima. Artinya terdapat pengaruh gaya belajar terhadap penguasaan kosakata bahasa Inggris peserta didik.
\end{abstract}

Kata Kunci: Gaya Belajar, Auditori, Kinestetik, Visual, Kosakata

\section{PENDAHULUAN}

\section{LATAR BELAKANG}

Manusia sebagai makhluk sosial sangat memerlukan interaksi dan komunikasi dalam kehidupannya. Interaksi dan komunikasi hanya mungking dilakukan apabila mereka memiliki suatu bahasa yang dapat saling dipahami. Bahasa yang dimaksud dapat melalui bahasa lisan, tulisan bahkan mungkin bahasa tubuh atau bahasa isyarat yang memungkinkan lawan bicara juga dapat memahami dengan baik apa yang ingin disampaikan. Dalam berkomunikasi, setiap individu harus dapat menyampaikan pikiran dan perasaan baik secara lisan maupun tulisan.

Bahasa merupakan suatu alat komunikasi antar anggota masyarakat dalam menyampaikan pikiran dan perasaan. Menurut Owen dalam Stiawan (2006:1) Language can be defined as a 
society shared combination of those symbols and rules governed combination of those symbols. artinya bahasa didefinisikan sebagai kode yang diterima secara social atau system konvensional untuk menyampaikan konsep melalui kegunaan simbol-simbol yang dikendaki dan kombinasi symbol-simbol yang diatur oleh ketentuan.

Bahasa Inggris termasuk bahasa internasional yang banyak dipergunakan untuk berkomunikasi antar bangsa. oleh karena itu, bahasa Inggris dianggap penting dalam penyerapan dan pengembangan ilmu pengetahuan dan tekhnologi dan seni budaya antar bangsa. Jadi bahasa Inggris merupakan suatu kebutuhan bagi para peserta didik untuk mampu berkomunikasi di berbagai situasi dalam berbahasa Inggris.

Tujuan mengajar bahasa adalah agar peserta didik mampu menggunakan bahasa itu sendiri dalam berkomunikasi. Komunikasi dapat terjadi apabila ada dua orang atau lebih yang melakukannya dengan cara membaca, mendengar, berbicara atau menulis. Dan untuk dapat melakukan komunikasi dengan empat cara tersebut dibutuhkan komponen lain seperti penguasaan kosakata, stuktur bahasa dan pengucapan yang baik.

Dalam mempelajari bahasa, khususnya bahasa Inggris seringkali peserta didik mengalami kesulitan. Kesulitan yang dialami peserta didik dalam mempelajari bahasa asing khususnya bahasa Inggris sangatlah beragam. Perbedaan penguasaan bahasa peserta didik dapat dipengaruhi oleh gaya belajar peserta didik yang berbeda juga. Menurut Keefe dalam jurnal yang ditulis oleh Narayanasamy (2000:3) mendefinisikan gaya belajar sebagai komposit ciri-ciri beberapa factor kognitif, efekttif dan psikologi yang menjadi indicator-indikator bagaimana seorang membuat persepsi dan berinteraksi serta respon dengan alam disekitarnya.

\section{TINJAUAN PUSTAKA \\ Hakikat Penguasaan Kosakata Bahasa Inggris}

Bahasa Inggris

Bahasa adalah suatu pengertian yang luas dan kompleks. Bahasa adalah suatu sistem. Bahasa merupakan sistem signal yang bekerja dengan simbolsimbol bunyi vokal dan digunakan oleh sekelompok orang untuk tujuan berkomunikasi.

Bahasa dibentuk oleh kaidah, aturan, serta pola yang tidak boleh dilanggar agar tidak menyebabkan gangguan pada saat berkomunikasi. Aturan dan pola-pola yang dibentuk mencakup tata bunyi, tata bentuk dan tata kalimat. Hal ini senada dengan pendapat Chomsky dalam buku English made Easy yang ditulis oleh Evelyn (2006: 45)

"Language is an intricate rule based system. There are the finite number of grammatical rules in the system and with a knowledge of these, an infinite number of sentences can be performed in the language."

Artinya, bahasa merupakan aturan sistem dasar. Pengetahuan tata bahasa yang dimiliki seseorang akan membuat orang tersebut sanggup memahami dan menciptakan kalimat yang tidak terbatas banyaknya.

Bahasa Inggris merupakan bahasa yang sangat kaya akan perbendaharaan kata, yang diperkirakan hampir mencapai dua juta kata. Hal ini diungkapkan oleh Evelyn (2006:32) "English is a language which has very wealth vocabulary, aproximately two million words."

Dalam Kamus Besar Bahasa Indonesia, Departemen pendidikan Nasional menyatakan bahwa: "bahasa 
adalah sistem lambang bunyi yang arbiter, yang digunakan oleh anggota suatu masyarakat untuk bekerja sama, berinteraksi, dan mengidentifikasikan diri." Hal ini senada dengan pendapat Cruse (2000:6) yang menyatakan bahwa:

"Natural human language is a complex sign system, 'designed' to ensure infinite expressive capacity, that is to say, there is nothing that is thinkable which cannot in principle be encoded (provided no limit is placed on the complexity of utterances).

Setelah seseorang menguasai bahasa ibunya, ia mempunyai kesempatan untuk mempelajari bahasa asing dalam rangka pengembangan dirinya ke suatu komunikasi yang lebih luas. Ada tiga tingkatan dalam mempelajari bahasa asing, yaitu: (1) Receiving knowledge, (2) fixing in the memory by repeating it, and (3) using knowledge by read practice.

Bahasa Inggris termasuk bahasa asing. Bahasa Inggris adalah bahasa Internasional yang sering digunakan oleh anggota masyarakat diberbagai penjuru dunia untuk berkomunikasi, bahasa Internasional adalah suatu bahasa yang digunakan oleh masyarakat dari negara yang berbeda untuk berkomunikasi dengan masyarakat dari negara lain. Hal tersebut senada dengan kegunaan bahasa yang diungkapkan oleh Cruse (2000:21)

"Language is used to communicate about things, happenings, and states of affairs in the world, and one way of approaching the study of meaning is to attempt to correlate expression in language with aspects of the world."

Akan tetapi, mempelajari suatu bahasa tidak hanya belajar dari tata bahasa saja, tetapi juga tentang kebudayaan yang berlaku dimasyarakat yang berbahasa itu.

Kosakata (Vocabulary)

Sebelum mempelajari suatu bahasa asing dengan lebih mendalam, seseorang sebaiknya mempelajari kosakata bahasa asing tersebut, karena kosakata merupakan landasan utama untuk berkomunikasi. Yang dimaksud dengan kosakata adalah jumlah kata yang dimiliki oleh suatu bahasa berdasarkan pengalaman para penutur asli. Setiap pengalaman, kejadian, benda dan ide mempunyai nama yang berbentuk kata. Perluasan kosakata sangat penting untuk setiap orang, karena kata merupakan alat untuk berkomunikasi dan dasar untuk berpikir.

Sejak masih kanak-kanak, manusia sudah mengenal kosakata karena manusia berhubungan dengan benda baru untuk dikenal dan dipelajari dalam setiap proses kehidupannya. Tumbuh dan berkembangnya kosakata yang dimilikinya terus berlanjut selama hidupnya.

Hampir setiap kata dalam bahasa Inggris memiliki arti yang berbeda tergantung dari pemakaian dalam kalimat. "Vocabulary as words which are related one to another so the meaning depends on the context.(Vivian Cook, 2006:34)"Artinya, kosakata adalah kata-kata yang saling berhubungan satu dengan yang lain. Makna tersebut tergantung dari konteks kalimatnya.

Sementara itu menurut Hornby dalam Oxford Advanced Learner's Dictionary mengemukakan;

(Hornby, 2003 :59) Vocabulary is (1) Total number of words which with rules for combining item make up language; (2) Word known to a used by a person, a trade profession, etc; (3) Book 
containing a list of words, usually with definition and translation."

Artinya, kosakata adalah jumlah kata yang dikombinasikan sesuai peraturan yang tepat untuk membentuk suatu bahasa; kata yang diketahui dan digunakan oleh seseorang; buku yang berisi daftar kata, biasanya dengan pengertian dan artinya.

Makna sebuah kata dapat berbeda apabila digunakan dalam konteks yang berbeda. Dengan perbendaharaan kata yang luas seseorang dapat mengerti dengan mudah apa yang didengar, dibaca maupun dikatakan seseorang, serta dapat berkomunikasi dengan jelas dan efektif. Kosakata dapat dipelajari dengan berbagai cara, sesuai dengan keterampilan guru dan media belajar yang ada dan menyenangkan.

\section{Pengertian Penguasaan}

Penguasaan merupakan sebuah proses, cara, perbuatan menguasai atau menguasakan. Penguasaan juga dapat dipahami sebagai pemahaman atau kesanggupan untuk menggunakan pengetahuan, dan kepandaian (artikata.com, 4 Februari 2016, 22.23). Sementara menurut Hajar aulia, Penguasaan adalah proses, cara, perbuatan menguasai atau menguasakan, pemahaman atau kesanggupan untuk menggunakan pengetahuan, kepandaian. Kemampuan seseorang dalam menguasai sesuatu hal merupakan sesuatu yang sangat baik dalam kelangsungan hidupnya dalam hal ini kgususnya menguasai suatu bahasa. Dengan penguasaan bahasa akan sangat menolong seseorang untuk bersosialisasi dan beradaptasi dengan sangat baik.

Penguasaan Kosakata Bahasa Inggris

Sebelum mempelajari suatu bahasa asing dengan lebih mendalam, seseorang sebaiknya mempelajari kosakata bahasa asing tersebut, karena kosakata merupakan landasan utama untuk berkomunikasi. Yang dimaksud dengan kosakata adalah jumlah kata yang dimiliki oleh suatu bahasa berdasarkan pengalaman para penutur asli. Setiap pengalaman, kejadian, benda dan ide mempunyai nama yang berbentuk kata. Perluasan kosakata sangat penting untuk setiap orang, karena kata merupakan alat untuk berkomunikasi dan dasar untuk berpikir. Sejak masih kanak-kanak, manusia sudah mengenal kosakata karena manusia berhubungan dengan benda baru untuk dikenal dan dipelajari dalam setiap proses kehidupannya. Tumbuh dan berkembangnya kosakata yang dimilikinya terus berlanjut selama hidupnya.

Hampir setiap kata dalam bahasa Inggris memiliki arti yang berbeda tergantung dari pemakaian dalam kalimat. "Vocabulary as words which are related one to another so the meaning depends on the context.(Vivian Cook, 2006:34)"Artinya, kosakata adalah kata-kata yang saling berhubungan satu dengan yang lain. Makna tersebut tergantung dari konteks kalimatnya.

Sementara itu menurut Hornby dalam Oxford Advanced Learner's Dictionary mengemukakan;

(Hornby, 2003 :59) Vocabulary is (1) Total number of words which with rules for combining item make up language; (2) Word known to a used by a person, a trade profession, etc; (3) Book containing a list of words, usually with definition and translation."

Artinya, kosakata adalah jumlah kata yang dikombinasikan sesuai peraturan yang tepat untuk membentuk suatu bahasa; kata yang diketahui dan digunakan oleh seseorang; buku yang berisi daftar kata, biasanya dengan pengertian dan artinya. 
Makna sebuah kata dapat berbeda apabila digunakan dalam konteks yang berbeda. Dengan perbendaharaan kata yang luas seseorang dapat mengerti dengan mudah apa yang didengar, dibaca maupun dikatakan seseorang, serta dapat berkomunikasi dengan jelas dan efektif. Kosakata dapat dipelajari dengan berbagai cara, sesuai dengan keterampilan guru dan media belajar yang ada dan menyenangkan.

\section{Hakikat Gaya Belajar}

Pengertian Gaya Belajar

Guru sebagai pengajar dan pendidik perlu mengengenal peserta didiknya dengan sangat baik. Setiap guru tidak dapat menyamakan perlakuan yang sama kepada setiap peserta didik, mengingat gaya belajar peserta didik yang berbeda. Guru harus mampu memahami gaya belajar setiap peserta didik, sehingga materi pelajaran juga dapat sampai kepada peserta didik dengan karakteristik dan gaya belajar yang berbeda agar proses belajar mengajar efektif. Gaya belajar adalah kecenderungan seseorang untuk menggunakan cara tertentu dalam belajar sehingga dapat belajar dengan baik (2012:34). Menurut Chatib dalam Sari (2014: 4) Gaya belajar anak seperti pintu pembuka. Setiap butir informasi yang masuk lewat pintu terbuka lebar, akan memudahkan anak memahami informasi tersebut.

Dalam bukunya yang berjudul "Pahami Gaya Belajar Anak", Andri Priyatna mengatakan bahwa: Gaya belajar adalah cara dimana anak - anak menerima informasi baru dan proses yang akan mereka gunakan untuk belajar. Ada beberapa type gaya belajar anak yang harus dipahami oleh guru sebagai tenaga pendidik. Sebagian anak dapat menerima informasi lebih baik secara visual atau biasa disebut visual learner, sebagian lagi secara auditory atau auditory learner, dan yang lain sangat mungkin lebih efektif menerima informasi dengan kinestetik atau dikatakan tactual learner.

Dengan adanya perbedaan gaya belajar yang dimiliki oleh setiap peserta didik, maka guru harus mampu memahami ciri dari masing-masing gaya belajar tersebut agar mampu lebih mengenal peserta didik yang mereka ajarkan. Type gaya belajar terdiri atas: gaya belajar visual, auditori, dan kinestetik.

\section{Gaya Belajar Visual (Visual Learner) \\ Visual Learner adalah gaya belajar} dimana gagasan, konsep, data dan informasi lainnya dikemas dalam bentuk gambar dan teknik. Mereka memiliki ketertarikan yang tinggi ketika diperlihatkan peta konsep dan ide peta, grafik, gambar, dan ilustrasi visual lainnya (2011:33). Pembelajar visual belajar lebih baik dari melihat dan membaca. Hal ini senada dengan pendapat Bire Ludji, dkk bahwa Gaya belajar visual membuat siswa belajar melalui melihat, memandangi, mengamati dan sejenisnya (2014:171)Pada gaya belajar ini dibutuhkan model atau peragaan, dan media pembelajaran dengan objek-objek yang berkaitan dengan pelajaran yang disampaikan.

Pembelajar visual dapat berpikir dengan lebih cepat ketika melihat gambar, diagram, CD interaktif, video, dan lain sebagainya yang membuat mereka dapat menangkap banyak informasi melalui apa yang mereka lihat, maka biasanya pembelajar visual suka mencatat dengan detail informasi yang mereka dapatkanakan tetapi mereka tidak belajar dari hasil pengulangan.

Ciri-ciri pembelajar visual adalah: (1) teliti terhadap yang detail, (2) mengingat dengan mudah apa yang dilihat, (3) mempunyai masalah dengan 
instruksi lisan, (4) tidak mudah terganggu dengan suara gaduh, (5) pembaca cepat dan tekun, (6) lebih suka metode demonstrasi daripada ceramah, (7) sulit memilih kata ketika menyampaikan gagasan, (8) rapi dan teratur, dan $(\mathrm{j})$ penampilan sangat penting.

$$
\text { Andri Priyatna (2013:11) }
$$

mengatakan bahwa pembelajar visual mudah terganggu dan tidak sadar tentang waktu, biasanya mereka kreatif dan berbakat dalam bidang tekhnologi, matematis, atau emosional sehingga mereka juga seringkali sensitif terhadap guru. Perkembangannya cenderung tidak merata (acynchronous) sehingga mungkin memiliki nilai rapor yang sangat berbeda atau tidak rata, akan tetapi mereka dapat menguasai bahasa melalui penalaran.

\section{Gaya Belajar Auditif (Auditory Learner)}

Auditory Leaarner adalah suatu gaya belajar dimana siswa belajar lebih baik dengan cara mendengarkan (2011:34). Diperkirakan 30\% dari populasi termasuk pembelajar auditory. Pembelajar auditori adalah individu yang biasa mengumpulkan informasi lebih baik melalui suara, musik, pidato, dan komunikasi verbal (2013:50). Pembelajar auditori belajar lebih cepat dalam diskusi verbal dan mendengarkan apa yang dikatakan guru, mereka mencerna makna dari simbol atau suara, tinggi-rendahnya intonasi bicara, kecepatan bicara dan hal auditori lainnya. Mereka dapat menghafal lebih cepat melalui membaca teks dengan keras atau mendengarkan audio (2011:34).

Ciri-ciri pembelajar auditori adalah: (1) bicara pada diri sendiri saat bekerja, (2) konsentrasi mudah terganggu oleh suara ribut, sehingga sulit belajar dalam suasana bising, (3) senang bersuara keras ketika membaca, (4) sulit menulis, tapi mudah bercerita, (5) pembicara yang fasih, (6) lebih suka musik daripada lukisan, (7) bicara dalam irama yang berpola, (8) lebih suka gurauan lisan daripada membaca buku humor, (9) mudah menirukan nada, irama, dan nada suara.

Diperkirakan 20\% dari seluruh peserta didik dikelas mempunyai gaya belajar auditori. Karena itu penting bagi guru untuk menumbuhkan kekuatan mereka sambil mengendalikan keinginan untuk berbicara dengan temannya didalam kelas. Sehubungan dengan hal itu, maka strategi mengajar bagi guru adalah (2013:62):

1. Lebih banyak memberi pertanyaan lisan untuk peserta didik dengan gaya belajar auditori

2. Selama pelajaran berlangsung, mintalah peserta didik auditori untuk mengulang materi yang disampaikan dengan kata-katanya sendiri

a. Berikan mereka pilihan untuk ujian lisan atau tulisan

b. Membedakan strategi mengajar saat member materi, pesaerta didik auditori dengan kerja kelompok, eksperimen, proyek ataupun drama sehingga mereka dapat aman dalam elemen social mereka

c. Berikan imbalan atau reward untuk setiap partisipasi mereka didalam kelas

d. Mengatur nada suara, infleksi dan bahasa tubuh saat memberi materi pelajaran didalam kelas.

\section{Gaya Pembelajar Kinestetik (Tactual} Learner)

Tactual Learner adalah siswa yang belajar dengan melakukan, menyentuh, merasa, bergerak, dan mengalami pembelajar kinestetik sangat sulit untuk duduk diam berjam-jam karena keinginan mereka untuk beraktivitas dan mengeksplorasi sangatlah kuat. Maka, 
pembelajaran yang dibutuhkan harus bersifat kontekstual dan praktik.

Ciri-ciri Pembelajar Kinestetik adalah: (1) berbicara perlahan, (2) menanggapi perhatian fisik, (3) menyentuh orang untuk mendapat perhatian, (4) banyak bergerak dan selalu berorientasi pada fisik, (5) menggunakan jari sebagai petunjuk dalam membaca, (6) banyak menggunakan isyarat tubuh, (7) tidak bisa duduk diam dalam waktu lama, (8) menyukai permainan yang menyibukkan, (9) selalu ingin melakukan sesuatu, dan (10) tidak mudah mengingat letak geografi.

Kebanyakan anak yang berusia muda tergolong pembelajar kinestetik. Dengan kata lain, mereka mempelajari dunia yang ada dengan menyentuh, merasakan, bergerak, dan mengalaminya secara langsung. Anak-anak dengan gaya belajar kinestetik sampai dewasa mungkin akan menjadi seorang penari, atlet, dokter bedah, pengrajin atau musisi. Tips atau saran belajar yang baik untuk mereka adalah terlibat angsung dengan media pembelajaran atau tool yang bias mereka pegang dan dimainkan sebagai alat bantu belajar, seperti sempoa, geoboard (untuk melatih bentuk-bentuk geometris), globe dan peta, dan lain sebagainya.

Peserta didik dengan gaya belajar ini dapat berkembang di sekolah. Berikut adalah saran untuk membantu mereka belajar disekolah:

1. Masukkan mereka ke kelas drama disekolah, seni dramatis dapat menjadi outlet yang bagus untuk mereka

2. Berikan mereka peluang untuk menjelajahi area luar kelas, atau biarkan mereka berwisata alam seperti dipantai, saat berjalan dipasir atau menyentuh kerang mereka sedang belajar.
3. Dorong mereka untuk rajin membuat catatan, menggambar diagram atau membuat model-model.

\section{METODE PENELITIAN}

Penelitian ini dilaksanakan di Sekolah Menengah Pertama (SMP) Mardi Yuana Bogor. Dilaksanakan dalam waktu tiga bulan pada tahun 2016. Metode yang digunakan dalam penelitian ini adalah metode eksperimen dengan teknik kelas tersampling. Sampel pada penelitian ini berjumlah 64 peserta didik yang diambil dari populasi terjangkau yaitu kelas dengan prestasi belajar yang cukup baik dan rajin.

\section{METODE PENGUMPULAN DATA Variabel Penelitian}

Pada penelitian ini ditentukan 2 variabel yaitu:

Variabel bebas: Gaya Belajar peserta $\operatorname{didik}(\mathrm{A} 1, \mathrm{~A} 2, \mathrm{~A} 3)$

Variabel Terikat: Penguasaan Kosakata Bahasa Inggris (Y)

\section{Sumber Data}

Data adalah hasil pencatatan peneliti, baik berupa fakta maupun angka. Sebagai sumber data, telah ditentukan data yang diperoleh yaitu hasil tes penguasaan kosakata bahasa inggris peserta didik dan hasil tes gaya belajar peserta didik melalui angket yang diberikan dan telah divalidasi sebelumnya.

\section{Teknik Pengumpulan Data}

Untuk memperoleh data tersebut diatas, diperlukan teknik atau metode pengumpulan data agar data yang diperoleh relevan atau berhubungan dengan masalah penelitian. Metode pengumpulan data adalah cara-cara yang dapat digunakan oleh peneliti untuk mengumpulkan data (arikunto: 2002). Yang merupakan metode atau teknik 
pengumpulan data adalah dengan angket, wawancara atau interview, pengamatan atau observasi, ujian atau tes dan dokumentasi. Berdasarkan teori tersebut, maka teknik pengumpulan data pada penelitian ini adalah dengan angket dan tes berbentuk pilihan ganda.

\section{HASIL DAN PEMBAHASAN}

\section{HASIL PENELITIAN}

\section{Data Penguasaan Kosakata Bahasa} Inggris Peserta Didik

1. Gaya Belajar Auditori

Berdasarkan data mengenai tes penguasaan kosakata bahasa Inggris peserta didik dengan gaya belajar Auditori yang dilakukan terhadap 27 peserta didik dengan menggunakan SPSS 16.0, maka didapat data sebagai berikut:

Tabel 1.1

Distribusi Frekuensi Peserta didik dengan Gaya Belajar Auditori

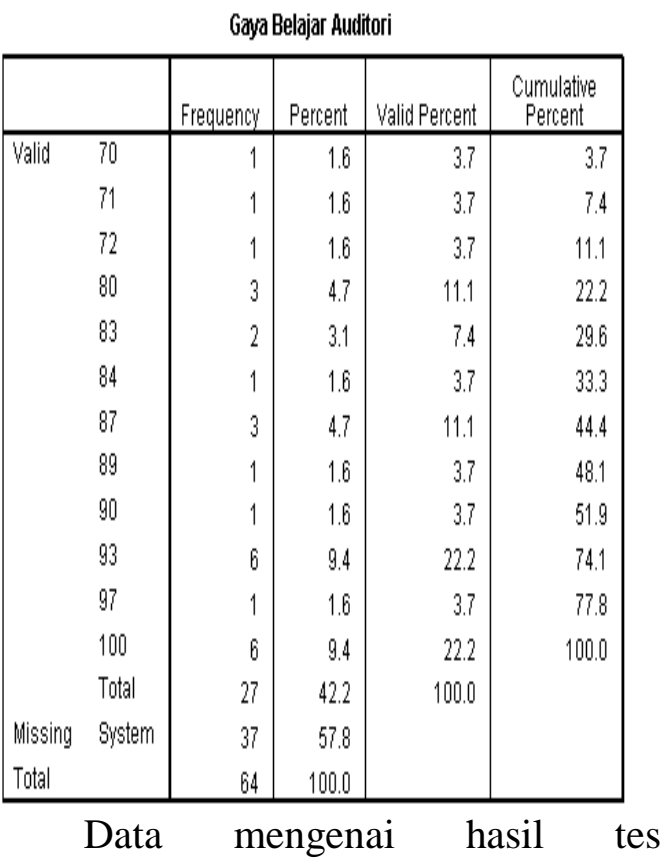
penguasaan kosakata bahasa Inggris peserta didik dikelas dengan gaya belajar auditori yang dilakukan terhadap 27 responden dengan menggunakan SPSS 16.0, maka didapat nilai rata-rata (mean) sebesar 88,81 dengan nilai tengah (median) 90,00 dan nilai yang sering muncul (modus) 93,00 dengan rentang nilai terletak pada angka minimum 70,00 dan maksimum 100,00. Hasil tersebut dapat dilihat pada table 5.2 dibawah ini:

\section{Tabel 1.2}

Analisis Deskriptif Penguasaan Kosakata Peserta didik dengan Gaya Belajar auditori

\section{Statistics}

\begin{tabular}{|l|r|}
\hline Nava Belaiar Auditori & \multicolumn{1}{c|}{ Valid } \\
\multicolumn{1}{|c|}{ Missing } & 27 \\
Mean & 37 \\
Median & 88.81 \\
Mode & 90.00 \\
Std. Deviation & $93^{2}$ \\
Variance & 9.224 \\
Minimum & 85.080 \\
Maximum & 70 \\
\hline
\end{tabular}

a. Multiple modes exist. The smallest value is shown

Hasil tersebut dapat terlihat lebih jelas dengan menggunakan histogram di bawah ini.

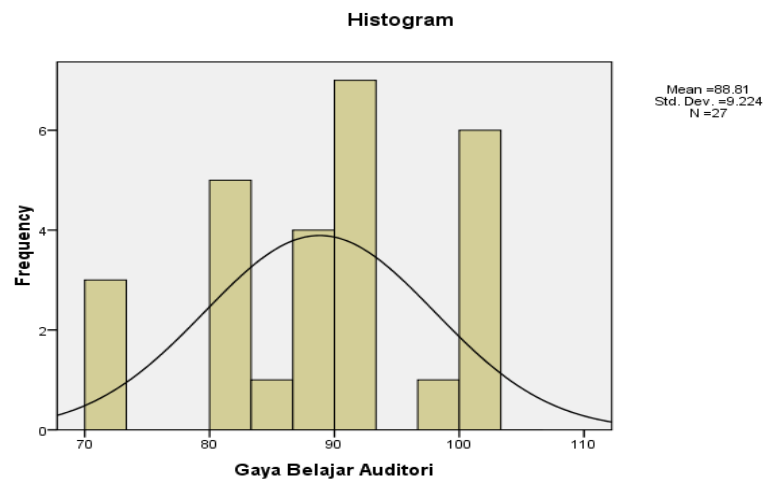

Gambar 1.1

Histogram Penguasaan Kosakata Peserta didik dengan Gaya Belajar Auditori

2. Gaya Belajar Kinestetik

Berdasarkan data mengenai tes penguasaan kosakata bahasa Inggris peserta didik dengan gaya belajar kinestetik yang dilakukan terhadap 18 peserta didik dengan menggunakan SPSS 16.0, maka didapat data sebagai berikut: 
Tabel 1.3

Distribusi Frekwensi Penguasaan Kosakata Peserta didik dengan Gaya Belajar Kinestetik

Gaya Belajar Kinestetik

\begin{tabular}{|c|c|c|c|c|c|}
\hline & & Frequency & Percent & Valid Percent & $\begin{array}{l}\text { Cumulative } \\
\text { Percent }\end{array}$ \\
\hline \multirow[t]{15}{*}{ Valid } & 50 & 1 & 1.6 & 5.6 & 5.6 \\
\hline & 54 & 1 & 1.6 & 5.6 & 11.1 \\
\hline & 67 & 1 & 1.6 & 5.6 & 16.7 \\
\hline & 70 & 2 & 3.1 & 11.1 & 27.8 \\
\hline & 72 & 1 & 1.6 & 5.6 & 33.3 \\
\hline & 77 & 1 & 1.6 & 5.6 & 38.9 \\
\hline & 78 & 1 & 1.6 & 5.6 & 44.4 \\
\hline & 80 & 3 & 4.7 & 16.7 & 61.1 \\
\hline & 81 & 1 & 1.6 & 5.6 & 66.7 \\
\hline & 83 & 1 & 1.6 & 5.6 & 72.2 \\
\hline & 84 & 1 & 1.6 & 5.6 & 77.8 \\
\hline & 86 & 1 & 1.6 & 5.6 & 83.3 \\
\hline & 87 & 2 & 3.1 & 11.1 & 94.4 \\
\hline & 91 & 1 & 1.6 & 5.6 & 100.0 \\
\hline & Total & 18 & 28.1 & 100.0 & \\
\hline Missing & System & 46 & 71.9 & & \\
\hline Total & & 64 & 100.0 & & \\
\hline
\end{tabular}

Data mengenai hasil tes penguasaan kosakata bahasa Inggris peserta didik dikelas dengan gaya belajar kinestetik yang dilakukan terhadap 18 responden dengan menggunakan SPSS 16.0, maka didapat nilai rata-rata (mean) sebesar 76,50 dengan nilai tengah (median) 80,00 dan nilai yang sering muncul (modus) 80,00 dengan rentang nilai terletak pada angka minimum 50,00 dan maksimum 91,00. Hasil tersebut dapat dilihat pada table 5.4 dibawah ini:

Tabel 1.4

Analisis Deskriptif Penguasaan Kosakata Peserta didik Gaya Belajar Kinestetik

\section{Statistics}

Gava_Belajar Kinestetik
\begin{tabular}{|l|r|}
\hline \multicolumn{1}{|c|}{ Valid } \\
Missing & 18 \\
Mean & 46 \\
Median & 76.50 \\
Mode & 80.00 \\
Std. Deviation & 80 \\
Variance & 11.068 \\
Minimum & 122.500 \\
Maximum & 50 \\
\hline
\end{tabular}

Hasil tersebut dapat dilihat dengan lebih jelas menggunakan histogram penguasaan Kosakata bahasa Inggris peserta didik dibawah ini:

$$
\text { Histogram }
$$
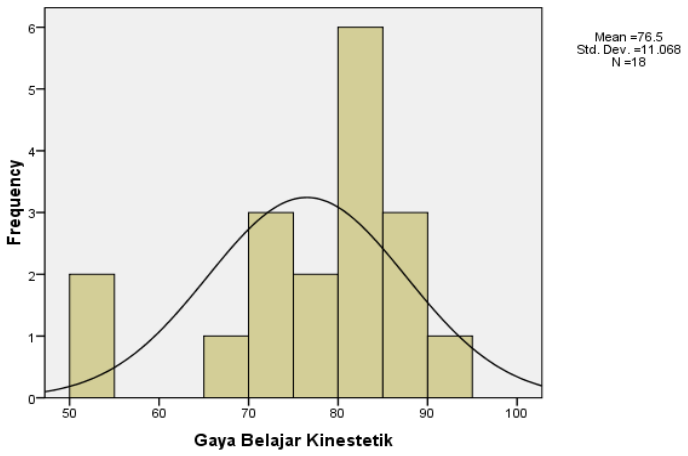

Gambar 1.2

Histogram Penguasaan Kosakata Peserta didik dengan Gaya Belajar Kinestetik

3. Gaya Belajar Visual

Berdasarkan data mengenai tes penguasaan kosakata bahasa Inggris peserta didik dengan gaya belajar visual yang dilakukan terhadap 19 peserta didik dengan menggunakan SPSS 16.0, maka didapat data sebagai berikut:

Tabel 1.5

Distribusi Frekwensi Penguasaan Kosakata Peserta didik dengan Gaya Belajar Visual

Gaya Belajar Visual

\begin{tabular}{|ll|r|r|r|r|}
\hline & & Frequency & Percent & Valid Percent & $\begin{array}{c}\text { Cumulative } \\
\text { Percent }\end{array}$ \\
\hline Valid & 40 & 1 & 1.6 & 5.3 & 5.3 \\
& 57 & 4 & 6.2 & 21.1 & 26.3 \\
& 60 & 1 & 1.6 & 5.3 & 31.6 \\
61 & 1 & 1.6 & 5.3 & 36.8 \\
& 62 & 1 & 1.6 & 5.3 & 42.1 \\
& 67 & 1 & 1.6 & 5.3 & 47.4 \\
& 70 & 1 & 1.6 & 5.3 & 52.6 \\
& 72 & 2 & 3.1 & 10.5 & 63.2 \\
& 76 & 1 & 1.6 & 5.3 & 68.4 \\
& 80 & 1 & 1.6 & 5.3 & 73.7 \\
& 83 & 1 & 1.6 & 5.3 & 78.9 \\
& 84 & 1 & 1.6 & 5.3 & 84.2 \\
& 85 & 1 & 1.6 & 5.3 & 89.5 \\
& 93 & 2 & 3.1 & 10.5 & 100.0 \\
& Total & 19 & 29.7 & 100.0 & \\
Missing & System & 45 & 70.3 & & \\
Total & & 64 & 100.0 & & \\
\hline
\end{tabular}

Data mengenai hasil tes penguasaan kosakata bahasa Inggris 
peserta didik dikelas dengan gaya belajar visual yang dilakukan terhadap 19 responden dengan menggunakan SPSS 16.0, maka didapat nilai rata-rata (mean) sebesar 69,79 dengan nilai tengah (median) 70,00 dan nilai yang sering muncul (modus) 57,00 dengan rentang nilai terletak pada angka minimum 40,00 dan maksimum 93,00. Hasil tersebut dapat dilihat pada table 5.6 dibawah ini:

Tabel 1.6

Analisis Deskriptif Penguasaan Kosakata Peserta didik dengan Gaya Belajar Visual Statistics

\begin{tabular}{|l|r|}
\hline Gava Belaiar Visual & Valid \\
Mean Missing & 19 \\
Median & 45 \\
Mode & 69.79 \\
Std. Deviation & 70.00 \\
Variance & 57 \\
Minimum & 14.184 \\
Maximum & 201.175 \\
\hline \multicolumn{2}{|c|}{ Histogram } \\
\hline
\end{tabular}

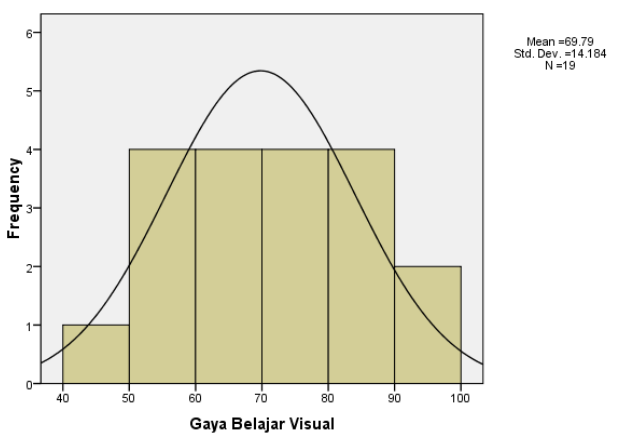

Gambar 1.3

Histogram Penguasaan Kosakata Peserta didik dengan Gaya Belajar Visual

\section{Pengujian Persyaratan Analisis Data}

1. Pengujian Normalitas Data

Uji normalitas dilakukan
dengan menggunakan analisis
Kolmogorov Smirnov pada SPSS 16.0. Untuk menentukan apakah data berdistribusi normal atau tidak, ditentukan dalam criteria berikut:

Jika nilai sig > 0,05; Maka data berdistribusi normal
Jika nilai sig < 0,05; Maka data tidak berdistribusi normal

Data hasil perhitungan uji normalitas, dinyatakan dalam table 5.7 di bawah ini:

Tabel 1.7

Hasil Uji Normaliatas One-Sample Kolmogorov-Smirnov Test

\begin{tabular}{|c|c|c|c|c|}
\hline & & $\begin{array}{l}\text { Gava Belajar } \\
\text { Auditori }\end{array}$ & $\begin{array}{c}\text { Gava Belajar } \\
\text { Kinestetilk }\end{array}$ & $\begin{array}{c}\text { Gava Belajar } \\
\text { Yisual }\end{array}$ \\
\hline$N$ & & 27 & 18 & 19 \\
\hline \multirow[t]{2}{*}{ Normal Parameters ${ }^{2}$} & Mean & 88.81 & 76.50 & 69.79 \\
\hline & Std. Deviation & 9.224 & 11.068 & 14.184 \\
\hline \multirow[t]{3}{*}{ Most Extreme Differences } & Absolute & .156 & .185 & .131 \\
\hline & Positive & .113 & .116 & .130 \\
\hline & Negative & .156 & -185 & .131 \\
\hline Kolmogoror-Smimov Z & & .813 & .784 & .571 \\
\hline Asymp. Sig. (2-tailed) & & .523 & .571 & .900 \\
\hline
\end{tabular}

Dari tabel di atas terlihat nilai sig untuk variable Penguasaan kosakata peserta didik dengan gaya belajar auditori adalah 0,523; sementara untuk variable penguasaan kosakata peserta didik dengan gaya belajar kinestetik adalah 0,571 dan untuk variable penguasaan kosakata peserta didik dengan gaya belajar visual adalah 0,900. Maka Dari tabel 5.7. tersebut dapat dikatakan bahwa seluruh variabel memiliki nilai sig >0,05; atau dengan kata lain, seluruh variabel yang diteliti berdistribusi normal.

2. Pengujian Homogenitas

Uji homogenitas dilakukan untuk menguji apakah terdapat kesamaan (homogen) atau ketidaksamaan varians populasi antara kelompok eksperimen dan kelompok control. Apabila nilai sig > 0,05 maka varian antar kelompok dinyatakan homogeny. Dengan Kriteria:

Ho : Varian antar kelompok Homogen

H1 : Varian antar kelompok tidak homogeny

Pengujian homogenitas varians dilakukan dengan SPSS 16.0, dan hasilnya adalah: 
Tabel 1.8

Homogenitas

Test of Homogeneity of Variances

Penquasaan Kosakata
\begin{tabular}{|r|r|r|c|}
\hline $\begin{array}{c}\text { Levene } \\
\text { Statistic }\end{array}$ & df1 & df2 & Siq. \\
\hline 2.284 & 2 & 61 & .110 \\
\hline
\end{tabular}

Dari table di atas didapat nilai sig 0,110 maka Ho yang menyatakan varian antar kelompok homogeny diterima dan H1 yang menyatakan varian antar kelompok tidak homogen ditolak. Ho diterima karena nilai sig 0,110>0,05, maka varian dikatakan homogen.

\section{Pengujian Hipotesis}

a. Uji Anava

Setelah dilakukan uji persyaratan analisis data, maka langkah berikutnya adalah uji hipotesis. Uji hipotesis pada penelitian ini dilakukan dengan ANAVA melalui SPSS 16.0 dengan criteria apabila nilai sig < 0,05 maka ada pengaruh gaya belajar terhadap penguasaan kosakata bahasa Inggris peserta didik. Tetapi apabila nilai sig > 0,05 maka tidak ada pengaruh gaya belajar terhadap penguasaan kosakata bahasa Inggris peserta didik. Hipotesis yang diuji adalah:

Ho : Tidak Terdapat Pengaruh Gaya Belajar Terhadap Penguasaan Kosakata

H1 : Terdapat Pengaruh Gaya Belajar Terhadap Penguasaan Kosakata

Jika sig < 0,05 maka Ho ditolak dan $\mathrm{H} 1$ ditema

Jika sig > 0,05 maka Ho diterima dan $\mathrm{H} 1$ ditolak

Atau

Jika Fhit > Ftab maka Ho di tolak dan $\mathrm{H} 1$ diterima
Jika Fhit < Ftab maka Ho diterima dan $\mathrm{H} 1$ ditolak

Tabel 1.9

Uji Hipotesis

ANOVA

Pencuasaan Kosakata
\begin{tabular}{|l|r|r|r|r|r|}
\hline & \multicolumn{1}{c|}{$\begin{array}{c}\text { Sum of } \\
\text { Squares }\end{array}$} & \multicolumn{1}{c|}{ df } & Mean Square & F & Sig. \\
\hline Between Groups & 4293.627 & 2 & 2146.814 & 16.544 & .000 \\
Within Groups & 7915.732 & 61 & 129.766 & & \\
Total & 12209.359 & 63 & & & \\
\hline
\end{tabular}

Berdasarkan tabel di atas dapat diputuskan bahwa Ho yang menyatakan tidak ada pengaruh gaya belajar terhadap penguasaan kosakata bahasa Inggris ditolak dan $\mathrm{H} 1$ yang menyatakan terdapat penngaruh gaya belajar terhadap penguasaan kosakata bahasa Inggris diterima. Dari table diatas dapat terlihat jelas sig $0,000<$ 0,05 dan Fhit $>$ F table atau 16,544 > 3,148. Maka Ho ditolak dan $\mathrm{H} 1$ diterima.

b. Uji Lanjut

Uji lanjut dilakukan dengan Uji Post Hoc yang dilakukan melalui SPSS 16.0. Dari uji lanjut tersebut didapat:

Tabel 1.10

Uji Post Hoc

Muttiple Comparisons

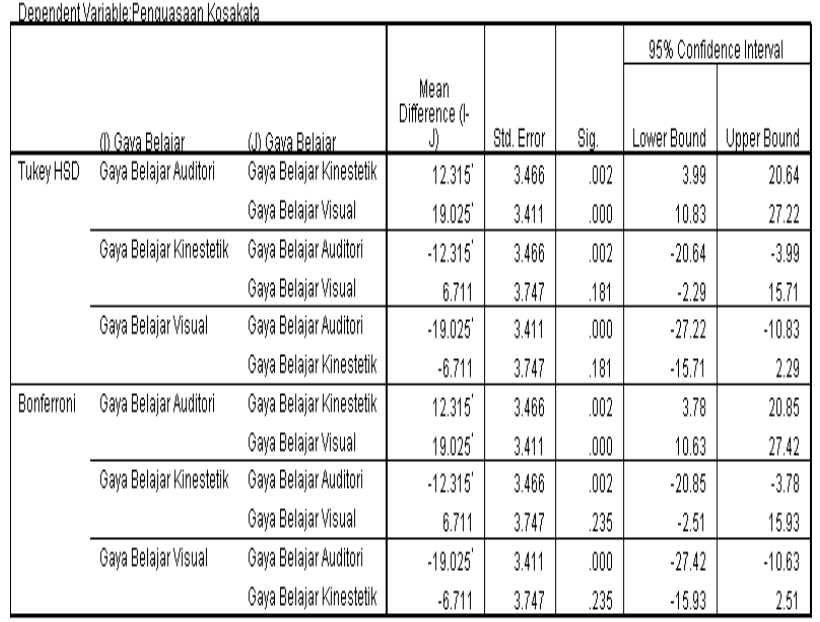

*.The mean difference is significant at the 0.05 level 
1) Terdapat Perbedaan yang Signifikan peserta didik dengan gaya belajar auditori dengan gaya belajar kinestetik

2) Terdapat Perbedaan yang Signifikan antara peserta didik gaya belajar auditori dengan gaya belajar visual

3) Tidak Terdapat Perbedaan yang Signifikan antara peserta didik gaya belajar Kinestetik dengan gaya belajar Visual

\section{PEMBAHASAN PENELITIAN}

\section{HASIL}

Penelitian ini bertujuan untuk mengetahui pengaruh gaya belajar terhadap penguasaan kosakata bahasa Inggris peserta didik. Berdasarkan hasil penelitian yang telah dilakukan, terlihat jelas bahwa peserta didik dengan gaya belajar auditori menguasai kosakata dengan lebih baik daripada peserta didik dengan gaya belajar visual dan kinestetik. Hal ini dibuktikan dengan perolehan nilai rata-rata peserta didik dengan gaya belajar auditori sebesar 88,81 dengan nilai tengah (median) 90,00 dan nilai yang sering muncul (modus) sebesar 93,00. Angka minimum peserta didik dengan gaya belajar auditori juga terbilang baik, yaitu 70 dan nilai maksimum 100. Berbeda dengan peserta didik dengan gaya belajar kinestetik memperoleh nilai minimum 50,00 dan nilai maksimum 91,00. Sementara itu peserta didik dengan gaya belajar visual memperoleh nilai minimum 40,00 dan nilai maksimum 93,00. Perbedaan tersebut juga terlihat dari uji Post Hoc pada table 5.10 diatas.

Setiap peserta didik memiliki gaya belajar masing-masing. Gaya belajar tidak selalu bicara bahwa peserta didik hanya dapat atau mampu melakukan satu hal atau satu bidang saja, tapi merupakan cara yang mereka pilih untuk mereka gunakan dalam memahami atau mengerti suatu hal. Hal ini senada dengan yang dikatakan Sternberg dalam jurnal yang ditulis oleh hatami mengatakan A learning style is not in itself ability but rather a preferred way of using one's abilities. Individuals have different learning styles that is, they differ in their natural, habitual and preferred way(s) of absorbing, processing and retaining new information and skils'. Individu memiliki gaya belajar yang berbeda karena mereka juga memiliki sebuah natur atau bawan alamiah yang berbeda, kebiasaan dan pilihan cara yang berbeda dalam menerima dan memproses setiap informasi baru yang mereka terima.

Gaya belajar adalah kecenderungan seseorang untuk menggunakan cara tertentu dalam belajar sehingga dapat belajar dengan baik (Isriani, 2012:34). Maka harus dipahami bahwa tidak ada yang salah dengan gaya belajar yang dimiliki oleh setiap peserta didik. Perlu pendekatan khusus, metode dan media pembelajaran yang menarik dan inofatif untuk memfasilitasi dan membantu proses belajar peserta didik mengerti dan menguasai kosakata bahasa Inggris peserta didik. Perbedaan gaya belajar juga mungkin mempengaruhi kemampuan peserta didik dalam berbagai bidang keahlian.

Dalam bukunya yang berjudul "Pahami Gaya Belajar Anak", Andri Priyatna mengatakan bahwa: Gaya belajar adalah cara dimana anak - anak menerima informasi baru dan proses yang akan mereka gunakan untuk belajar. Ada beberapa type gaya belajar anak yang harus dipahami oleh guru sebagai tenaga pendidik. Dalam satu kelas sangat mungkin terdiri dari peserta didik dengan gaya belajar yang berbeda, maka guru dituntut untuk menggunakan 
media pembelajaran yang bervariasi sesuai dengan variasi gaya belajar peserta didik, sehingga semua peserta didik dapat belajar dengan baik. Jadi, pada dasarnya semua anak pintar dan dapat belajar, hanya saja fasilitas yang dibutuhkan saat belajar berbeda sesuai dengan gaya belajar mereka masingmasing.

\section{SIMPULAN}

Terdapat perbedaan rerata penguasaan kosakata bahasa Inggris peserta didik dengan gaya belajar auditori, kinestetik dan visual. Dalam hal ini peserta didik dengan gaya belajar visual memiliki kemampuan menguasai kosakata tertinggi atau lebih baik jika dibandingkan dengan peserta didik dengan gaya belajar kinestetik dan visual. Sementara itu tidak terdapat perbedaan rerata yang signifikan antara peserta didik dengan gaya belajar kinestetik dan visual.

Berdasarkan simpulan penelitian maka beberapa saran terkait yang dapat penulis sampaikan adalah :

1. Sangat baik bagi guru atau pendidik untuk mengetahui terlebih dahulu gaya belajar apa yang dimiliki oleh masing-masing peserta didik mereka.

2. Guru atau pendidik sebaiknya mengajar dengan menggunakan media yang beragam untuk membantu peserta didik yang memiliki beragam gaya belajar dalam memahami materi yang diajarkan. Atau dengan kata lain, tidak terpaku pada satu alat atau metode belajar.

3. Guru atau pendidik diharapkan mampu mengarahkan peserta didik agar memaksimalkan kemampuan mereka berdasarkan gaya belajar masing-masing. Karena setiap gaya belajar tentu memiliki kelebihan dan kekurangan. Dengan arahan yang tepat dari guru atau pendidik, maka setiap peserta didik berpeluang besar untuk berprestasi di setiap bidang dengan cara masing-masing.

\section{DAFTAR PUSTAKA}

Bire L. A. dkk. (2014). Pengaruh Gaya Belajar Visual, Auditorial, dan Kinestetik Terhadap Prestasi Belajar Siswa. Jurnal Kependidikan, Volume 44 No. 2 (diakses Desember 2016)

Cruse A. (2000). Meaning in Language. New York: Oxford

Danim, S \& Khairil. (2010). Psikologi Pendidikan. Bandung: Alfabeta

Duderey, G. \& Hockly N. (2007). How to Teach English with Technology. Edinburgh gate: Longman

Hardini, I \& Puspitasari, D. (2012). Strategi Pembelajaran Terpadu Teori, Konsep dan Implementasi. Yogyakarta: Familia.

Hatami, S. (2013). Learning Styles. ELT Journal Advance access. Oxford

Hornby. (2003). Oxford Advanced Learner's Dictionary. Oxford: Oxford University

Kartika, S. A. (2014). Analisis Karakteristik Gaya Belajar VAK (Visual, Auditorial, Kinestetik) Mahasiswa Pendidikan Informatika Angkatan 2014. Jurnal Ilmiah Edutic Vol 1. No.1 (diakses Desember 2016)

Madsen, S. H. (1983). Techniques in Testing. Oxford: Oxford

Narbuko, C. \& Ahmadi, A. (2009). Metodologi Penelitian. Jakarta: Bumi Aksara 
Priyatna, A. (2013). Pahami Gaya Belajar Anak. Jakarta: Elex Media Komputindo

Rientje, E. (2006). English Made Easy. Jakarta: Kesaint Blanc

Supardi. (2012). Aplikasi Statistika dalam Penelitian. Jakarta: Ufuk

Supeno \& Elly. (2007). Teaching English as a Foreign Language. Jakarta: Indraprasta PGRI University

Thornbury, S. (2007). How to Teach Vocabulary. Edinburgh gate: Longman
Wena, M. (2009). Strategi Pembelajaran Inovatif Kontemporer. Jakarta: Bumi

Aksarahttp://wismasastra.wordpress.co $\mathrm{m} / 2009 / 05 / 25 /$ apa-bahasa-itusepuluh-pengertian-bahasamnurut-para-ahli/

University https://m.eltj.oxfordjournals.org www.scribd.com/doc/3932095/gayabelajar

http://fkip.wisnuwardhana.ac.id 